\title{
Peran Kualitas Layanan Dalam Menciptakan Loyalitas Mahasiswa
}

\author{
Dewa Nyoman Benni Kusyana ${ }^{(1)}$ \\ Putu Atim Purwaningrat ${ }^{(2)}$ \\ Milla Permata Sunny ${ }^{(3)}$ \\ (1)(2)(3) Fakultas Ekonomi Bisnis dan Pariwisata Universitas Hindu Indonesia \\ e-mail: benni.unhi@gmail.com \\ \begin{tabular}{|l|l|l|}
\hline Diterima: 3 Desember 2019 & Direvisi: 20 Januari 2020 & Disetujui: 25 Januari 2020 \\
\hline
\end{tabular}
}

\begin{abstract}
Quality of service plays an important role in the world of education, especially higher education, although there is still debate about the position of students as customers, but it is believed that the quality of service in higher education plays an important role in ensuring the survival of a university. The purpose of this study was to determine the effect of higher education service quality on the satisfaction and loyalty of FEBP UNHI students. The model of higher education service quality used in this study is HEdPERF which consists of five dimensions namely academic aspects, non-academic aspects, reputation, access, and program issues. The sample used was 119 students from management and accounting study programs with simple random sampling technique, and the analysis technique used was path analysis. The results obtained were (1) HEdPERF had a positive but not significant effect on student loyalty, (2) HEdPERF had a positive and significant effect on student satisfaction, (3) satisfaction had a positive and significant effect on student loyalty, and (4) satisfaction mediated the effect of HEdPERF on student loyalty.
\end{abstract}

Keywords: quality of service, HEdPERF, student loyalty, student satisfaction

\section{Pendahuluan}

Kemajuan suatu negara saat ini tidak bisa diukur hanya dengan mengandalkan banyaknya sumber daya alam (SDA) yang dimiliki, namun bergantung kepada kualitas sumber daya manusia (SDM) yang ada. Negara-negara minim SDA yang berhasil menjadi negara maju telah membuktikan hal tersebut seperti Singapura, Korea Selatan, Jepang, dan Norwegia. Pendidikan memegang peranan yang sangat vital, baik itu di negara maju maupun negara berkembang. Jika bagi negara maju pendidikan masih memegang peranan vital, maka bisa dibayangkan betapa pentingnya pendidikan bagi negara berkembang seperti Indonesia. Pada tahun 2019, Presiden Joko Widodo yang telah memasuki periode kedua kepemimpinannya memprioritaskan pembangunan SDM secara besar-besaran sebagai prioritas utama dalam menghadapi persaingan global dan cara yang dapat ditempuh untuk mewujudkan cita-cita tersebut adalah melalui pendidikan, baik 
pendidikan dasar, menengah, dan pendidikan tinggi atau di Indonesia lebih dikenal dengan istilah perguruan tinggi.

Pentingnya sektor perguruan tinggi disadari oleh pertimbangan memiliki peran yang penting dalam mengembangkan perekonomian setiap negara di dunia, tidak terkecuali Indonesia. Sebagai destinasi wisata kelas dunia, Bali juga menyadari pentingnya pendidikan terutama perguruan tinggi agar dapat menyediakan SDM berkualitas yang dapat menunjang sektor pariwisata di Bali khususnya dan Indonesia umumnya. Untuk dapat menyediakan SDM Bali yang berkualitas, maka di Bali juga terdapat universitas-universitas unggulan yang dapat diandalkan oleh masyarakat Bali untuk mengakses pendidikan yang lebih baik. Tabel 1 berikut akan memberikan gambaran mengenai peringkat universitas di Bali.

\section{Tabel 1. Peringkat Universitas di Bali}

\begin{tabular}{clc}
\hline No & \multicolumn{1}{c}{ Nama Universitas } & Lokasi \\
\hline 1 & Universitas Udayana & Badung \\
2 & Universitas Pendidikan Ganesha & Singaraja \\
3 & Institut Seni Indonesia Denpasar & Denpasar \\
4 & Universitas Mahasaraswati Denpasar & Denpasar \\
5 & Universitas Warmadewa & Denpasar \\
6 & Universitas Pendidikan Nasional & Denpasar \\
7 & Universitas Dhyana Pura & Badung \\
8 & Universitas Hindu Indonesia & Denpasar \\
9 & Universitas Ngurah Rai & Denpasar \\
10 & Universitas Dwijendra & Denpasar \\
11 & Universitas Panji Sakti & Singaraja \\
12 & Universitas Mahendradata & Denpasar \\
13 & Universitas Tabanan & Tabanan \\
14 & Universitas Teknologi Indonesia & Denpasar \\
\hline
\end{tabular}

Sumber : www.4icu.org

Berdasarkan Tabel 1 dapat diketahui bahwa Universitas Hindu Indonesia (UNHI) berada di posisi ke delapan dan tiga posisi teratas ditempati oleh Perguruan Tinggi Negeri (PTN) yaitu Universitas Udayana, Universitas Pendidikan Ganesha, dan Institut Seni Indonesia Denpasar. Berdasarkan Tabel 1 juga dapat dikemukakan bahwa berdasarkan peringkat, maka Perguruan Tinggi Swasta (PTS) di Bali belum ada satupun yang bisa menembus posisi tiga besar, dengan kata lain data tersebut bisa menimbulkan suatu persepsi bahwa kualitas PTS masih berada di bawah PTN sehingga akan muncul anggapan bahwa PTS hanya menerima mahasiswa yang tidak lulus ujian masuk PTN. Kondisi ini tentu tidak bagus bagi dunia pendidikan, khususnya pendidikan 
tinggi karena akan mempengaruhi kemudahan alumni suatu perguruan tinggi dalam mencari pekerjaan dan mengakibatkan perguruan tinggi sulit untuk mendapatkan mahasiswa (Salim, 2011).

Pendidikan tinggi adalah layanan murni yang membutuhkan jumlah kontak interpersonal yang lebih besar, karena penyediaan pendidikan tinggi adalah layanan dan mahasiswa diharapkan untuk mendanai biaya pendidikan mereka, tampaknya tepat bahwa universitas membuat perubahan dari orientasi produk, yaitu mengandalkan produk untuk dijual, menuju pendekatan pelanggan (Angell et al., 2008). Dalam konteks pendidikan tinggi, skala lima dimensi untuk mengukur kualitas layanan, "HEdPERF", yang mencakup aspek layanan akademik dan non-akademik, isu program, akses, dan reputasi dikembangkan oleh Abdullah (2005). Pentingnya kualitas layanan yang diberikan oleh perguruan tinggi harus disadari karena mengabaikan sifat dan pentingnya kualitas layanan terbukti memiliki dampak negatif bagi penyedia layanan di industri pendidikan tinggi, di mana kepuasan mahasiswa memainkan peran penting dalam keberhasilan universitas dan dapat bertindak sebagai alat penting dalam meningkatkan kualitas layanan yang dirasakan (Abdullah, 2006).

Kepuasan mahasiswa memainkan peran penting dalam menjamin kelangsungan hidup dan pengembangan universitas. Manajemen universitas berharap mahasiswa yang puas akan berbagi word of mouth positif, sebagaimana dilakukan oleh pelanggan yang puas, dan membantu universitas untuk menarik dan merekrut mahasiswa baru (Helgesen dan Nesset, 2007; Ganic et al, 2018), dan berharap dapat mempertahankan mahasiswa saat ini untuk mengembangkan kerja sama lebih lanjut dengan mahasiswa tersebut. Menurut rantai keuntungan layanan, kepuasan pelanggan mengarah pada loyalitas pelanggan (Bloemer \& de Ruyter, 2010). Mahasiswa kini dianggap memiliki peran baru yang berkaitan dengan dampaknya terhadap keberhasilan universitas dan perubahan posisi universitas dalam ekonomi dan masyarakat kontemporer, loyalitas mahasiswa telah terbukti memiliki peran yang sangat penting bersama dengan kualitas perguruan tinggi dan kepuasan mahasiswa (Ganic et al, 2018)

Sebagai salah satu PTS yang ada di Bali dan berada di urutan delapan, maka UNHI memiliki tugas yang cukup berat untuk dapat meningkatkan peringkatnya agar memiliki daya saing terhadap PTS lainnya, dan juga tentunya terhadap PTN yang ada di Bali. UNHI memiliki enam fakultas, di antaranya Teknologi Informasi dan Sains, Fakultas Teknik, Fakultas Kesehatan, Fakultas Ekonomi Bisnis dan Pariwisata, Fakultas Ilmu Agama Seni dan Budaya, serta Fakultas Pendidikan (www.unhi.ac.id). Di antara enam fakultas tersebut, Fakultas Ekonomi, Bisnis, dan Pariwisata (FEBP) UNHI yang terdiri atas dua program studi (prodi) yaitu Manajemen dan Akuntansi tercatat memiliki mahasiswa paling banyak hingga Tahun 2019. 
Penelitian ini bertujuan untuk (1) mengetahui pengaruh kualitas layanan pendidikan terhadap loyalitas mahasiswa, (2) mengetahui pengaruh kualitas layanan pendidikan terhadap kepuasan mahasiswa, (3) mengetahui pengaruh kepuasan terhadap loyalitas mahasiswa, dan (4) mengetahui peran kepuasan dalam memediasi pengaruh kualitas layanan terhadap loyalitas mahasiswa FEBP UNHI.

\section{Telaah Literatur dan Kajian Pustaka}

\section{Kualitas Layanan Pendidikan Tinggi}

Kualitas layanan dipandang menjadi dimensi penting dalam menciptakan daya saing (Ali et al.,2012) dan sering dilaporkan dalam literatur pemasaran jasa. Selama dua dekade terakhir, topik ini menjadi fokus utama para peneliti karena besarnya dampak yang ditimbulkan terhadap pelanggan dan organisasi (Seth et al., 2005; Sureshchandar et al., 2003). Awal konseptualisasi kualitas layanan dikemukakan oleh Juran pada tahun 1988 yang menggambarkannya sebagai memenuhi harapan pelanggan (Ali et al, 2018), sedangkan Zeithaml (1988) mendefinisikan peningkatan kualitas layanan atau keunggulan dalam pemberian layanan. Kualitas layanan dalam area pendidikan tinggi memegang peranan yang sangat penting karena merupakan sebuah fakta yang tidak dapat dihindarkan bahwa persepsi positif atas kualitas layanan memiliki dampak yang signifikan terhadap kepuasan mahasiswa (Alves dan Raposo, 2010). Berbeda dengan definisi kualitas layanan yang dikemukakan oleh Parasuraman pada tahun 1988 yang diterima secara universal, definisi kualitas layanan dalam pendidikan tinggi masih terus menjadi perdebatan (Becket dan Brookes, 2006).

Definisi kualitas pendidikan tinggi adalah tergantung pada berbagai pemangku kepentingan yang mengalami berbagai layanan berbeda yang disediakan oleh institusi pendidikan tinggi, di mana mahasiswa adalah pemangku kepentingan utama bagi semua lembaga pendidikan tinggi, maka pengalaman mahasiswa dalam terlibat dengan berbagai layanan yang disediakan selama tahun-tahun masa kuliah terdiri atas kualitas layanan (Jancey and Burns, 2013). Dalam penelitian kali ini, definisi kualitas layanan pendidikan yang diajukan adalah tindakan atau kegiatan yang dilakukan oleh lembaga pendidikan, baik tingkat universitas maupun fakultas untuk memenuhi harapan mahasiswa baik dari segi akademik maupun non akademik.

Pada Tahun 2005, dengan mempertimbangkan perkembangan dunia pendidikan secara global, sebuah skala pengukuran untuk mengukur kualitas layanan pendidikan dikembangkan oleh seorang peneliti bernama Firdaus Abdullah di Malaysia yang didasarkan atas model SERVPERF yang diberi nama Higher Education Performance atau HEdPERF (Silva et al, 2017). Penelitian yang dilakukan oleh Abdullah (2005) tersebut bertujuan untuk mengukur kualitas layanan secara 
spesifik dalam dunia pendidikan, khususnya pendidikan tinggi. Dalam penelitiannya, Abdullah (2005) mengusulkan bahwa HEdPERF untuk mengukur kualitas layanan pendidikan tinggi terdiri atas enam dimensi, yaitu (1) aspek akademik yang hanya terdiri atas tanggung jawab akademik, (2) aspek non akademik yang terdiri atas hal-hal penting yang memungkinkan mahasiswa menyelesaikan kewajiban belajar yang berkaitan dengan tugas staf non akademik, (3) isu program yang menekankan pentingnya menawarkan program akademik / spesialisasi yang berepitasi dan luas dengan struktur fleksibel dan silabus, (4) reputasi yang sarat dengan item yang menunjukkan pentingnya institusi pendidikan tinggi dalam memproyeksikan citra profesional, (5) akses yang terdiri atas item-item berkaitan dengan isu-isu seperti mudah didekati, kemudahan kebijaksanaan, ketersediaan dan kenyamanan, dan (6) pemahaman, yang berkaitan dengan memahami kebutuhan khusus siswa dalam hal layanan konseling dan kesehatan. Icli dan Anil (2014) mengemukakan bahwa HEdPERF adalah skala yang paling berkembang dalam literatur pengukuran kualitas layanan pendidikan tinggi.

\section{Kepuasan Mahasiswa}

Literatur tentang kepuasan pelanggan didasarkan pada berbagai definisi yang berkaitan dengan konsep seperti pengalaman atau kualitas layanan, harapan, nilai yang dirasakan dan konsekuensi evaluasi layanan (Ali dan Amin, 2014). Dalam konteks pendidikan tinggi, mahasiswa adalah pelanggan utama (Sultan dan Wong, 2013). Konsep menganggap mahasiswa sebagai pelanggan penyedia layanan pendidikan tinggi bukanlah hal baru. Berbagai peneliti telah menyarankan mahasiswa sebagai pelanggan utama dan mitra di sektor pendidikan tinggi sebagaimana mereka secara sadar memilih dan menggunakan layanan (Kuh dan Hu, 2001). Sebagai pelanggan utama, definisi kepuasan mahasiswa mengacu pada keadaan psikologis berupa kebahagiaan sebagai hasil dari evaluasi kinerja atribut layanan dalam konteks pendidikan tinggi (Sultan \& Wong, 2012). Sebagai pelanggan utama, kepuasan mahasiswa memegang peranan krusial terhadap keberlangsungan lembaga pendidikan. Aspek akademik dan non-akademik merupakan faktor yang menentukan kepuasan mahasiswa (Ibrahim et al, 2014).

Mengukur kepuasan mahasiswa sangat penting karena dapat berperan sebagai mekanisme umpan balik bagi manajemen organisasi. Berdasarkan umpan balik, strategi yang diperlukan dapat dirumuskan untuk menuju perbaikan (Hasan dan Shamsudin, 2019). Elliott dan Shin (2002), menggambarkan kepuasan mahasiswa sebagai "kesukaan evaluasi subyektif mahasiswa dari berbagai hasil dan pengalaman yang terkait dengan pendidikan. Kepuasan siswa terus dibentuk oleh pengalaman berulang dalam kehidupan kampus". Wu et al. (2010) mendefinisikan kepuasan sebagai keseluruhan hasil dari keyakinan dan sikap perilaku mahasiswa itu hasil dari semua manfaat yang dirasakan dan diterima oleh mahasiswa dengan menggunakan sistem campuran. 


\section{Loyalitas Mahasiswa}

Loyalitas pelanggan adalah aspek inti dari pemberian layanan karena mempertahankan pelanggan yang sudah ada dianggap lebih bermanfaat bagi penyedia layanan daripada mencoba menarik yang baru (Diab et al, 2016). Loyalitas mahasiswa didefinisikan sebagai perasaan keterikatan atau kasih sayang untuk staf universitas, fakultas, dan layanan mereka (Chang-Li, 2012). Studi-studi yang difokuskan pada loyalitas mahasiswa di sektor pendidikan tinggi, yang membantu pengelola perguruan tinggi untuk membuat program yang sesuai yang mempromosikan, membangun, mengembangkan dan mempertahankan hubungan jangka panjang yang sukses dengan mahasiswa saat ini dan alumni. Di layanan pendidikan, loyalitas membutuhkan pengembangan hubungan yang kuat dengan mahasiswa yang akhirnya memberikan dasar keuangan untuk kegiatan universitas di masa depan (Annamdevula dan Bellamkonda, 2016a). Seorang mahasiswa yang loyal akan bertahan sampai selesai belajar, mendorong orang lain dan menyebarkan berita positif dari mulut ke mulut. Siswa yang loyal tidak akan keluar dari universitas dan beralih ke universitas lain (Duque, 2013).

\section{HEdPERF dan Loyalitas Mahasiswa}

Kualitas layanan merupakan kunci utama untuk menciptakan kepuasan dan loyalitas mahasiswa (Said, 2017). Bukti bahwa kualitas layanan memiliki pengaruh langsung terhadap loyalitas ditunjukkan dalam penelitian oleh Caruana (2002) serta Huili dan Jing, (2012), clemes et al (2008), dan Jiewanto et al, (2012). Layanan yang berkualitas akan membuat seorang mahasiswa menjadi loyal kepada universitas (Annamdevula dan Bellakomda, 2016b)

H1: HEdPERF berpengaruh positif dan signifikan terhadap loyalitas mahasiswa

\section{HEdPERF dan Kepuasan Mahasiswa}

Kualitas layanan dan kepuasan terkait tetapi berbeda konsep. Kualitas terkait dengan sikap dan lebih tahan lama, sedangkan kepuasan terkait dengan proses konsumsi dan bersyarat (Lazibat et al, 2015). Berbagai penelitian telah membuktikan bahwa kualitas layanan merupakan faktor yang menciptakan kepuasan (Li et al, 2011; Dlacic et al, , 2013; Ho et al, 2013; Stukalina, 2012). Penelitian oleh Faizan et al, (2016) membuktikan bahwa semua lima dimensi kualitas layanan pendidikan tinggi dalam struktur HEdPERF mempengaruhi kepuasan mahasiswa. Carter (2014) mengemukakan bahwa kepuasan yang dirasakan mahasiswa pada dasarnya adalah merupakan aspek afektif yang meliputi 3 aspek, yaitu (1) model layanan pelanggan sebagai aspek afektif dari terjadinya interaksi antara tenaga pengajar (dosen) dan staf administrasi dengan mahasiswa, (2) model bahagia-produktif sebagai aspek afektif yang dirasakan mahasiswa karena adanya perasaan puas, menjadi produktif, dan loyal; (3) model investasi yaitu perwujudan segala bentuk upaya yang 
telah dilakukan untuk menempuh perkuliahan sama berharganya seperti investor yang melihat uang mereka dalam kaitannya dengan mendapatkan pengahragaan atas apa yang telah dikeluarkan.

H2: HEdPERF berpengaruh positif dan signifikan terhadap kepuasan mahasiswa

\section{Kepuasan dan Loyalitas Mahasiswa}

Penelitian yang dilakukan oleh Kheiry (2012), Usman dan Mokhtar (2016), serta Annamdevula dan Bellamkonda (2016a) menunjukkan bahwa kepuasan merupakan variabel yang berpengaruh signifikan terhadap loyalitas mahasiswa. Schertzer dan Schertzer (20040 dan MarzoNavarro (2005) mengemukakan bahwa mahasiswa yang puas akan menarik mahasiswa baru dengan melakukan word of mouth positif dan kembali ke universitas yang sama untuk melanjutkan ke jenjang yang lebih tinggi. Literatur menunjukkan bahwa kepuasan adalah faktor yang menonjol dalam menciptakan loyalitas (Ryu et al, 2012; Helgesen dan Nesset (2011).

H3: Kepuasan berpengaruh positif dan signifikan terhadap loyalitas

\section{Peran Kepuasan sebagai Mediasi}

Kualitas layanan memiliki kaitan yang sangat erat dengan kepuasan dan loyalitas mahasiswa, sehingga manajemen harus memperhatikan kualitas layanan yang ditawarkan (Helgesen dan Nesset, 2007). Bukti bahwa kualitas layanan memiliki tidak langsung terhadap loyalitas melalui kepuasan ditunjukkan dalam penelitian oleh Caruana (2002) serta Huili dan Jing, (2012), Clemes et al (2008), Annamdevula dan Bellamkonda (2016b), Ganic et al, (2018), dan Jiewanto et al, (2012). Kualitas layanan yang dirasakan dipandang sebagai kunci yang menentukan kepuasan dengan kemungkinan besar akan mengakibatkan loyalitas mahasiswa, di mana kepuasan bertindak sebagai mediasi di antara kulitas layanan dan loyalitas (Annamdevula dan Bellakomda, 2016a)

H4: Kepuasan memediasi pengaruh HEdPERF terhadap loyalitas mahasiswa

\section{Metode Penelitian}

Penelitian ini termasuk dalam jenis asosiatif yang bertujuan untuk mengetahui pengaruh kualitas layanan perguruan tinggi dengan menggunakan model HEdPERF terhadap kepuasan dan loyalitas mahasiswa FEBP UNHI. Populasi dalam penelitian ini adalah mahasiswa FEBP UNHI baik dari prodi Manajemen maupun Akuntansi yang saat ini sedang menempuh pendidikan pada semester 5 atau lebih tinggi. Kuisioner yang disebarkan adalah sebanyak 125 eksemplar dan yang kembali dengan jawaban lengkap sebanyak 119 eksemplar, 1 eksemplar tidak dijawab dengan lengkap, dan 5 eksemplar tidak kembali. Pemilihan populasi dilakukan dengan pertimbangan bahwa mahasiswa yang telah menempuh perkuliahan hingga semester 5 atau lebih dari itu telah merasakan kualitas layanan yang disediakan oleh FEBP UNHI selama lebih dari 2 tahun sehingga 
memiliki pengalaman atau interaksi yang lebih banyak dibandingkan dengan yang menempuh perkuliahan kurang dari 2 tahun. Teknik pengambilan sampel menggunakan simple random sampling yang artinya setiap anggota populasi memiliki peluang yang sama untuk dijadikan sampel.

Obyek penelitian ini adalah HEdPERF yang berperan sebagai variabel bebas, terdiri atas lima dimensi meliputi (1) aspek akademik yang terdiri atas 9 indikator, (2) aspek non akademik terdiri atas 12 indikator, (3) reputasi yang dijabarkan ke dalam 7 indikator pernyataan, (4) akses yang dijabarkan ke dalam 7 indikator pernyataan, dan (5) isu program yangterdiri atas 5 indikator pernyataan. Variabel HEdPERF diadaptasi dari Abdullah (2005, 2006; dan Law, 2013). Berikutnya adalah variabel mediasi yaitu kepuasan mahasiswa yang didefinisikan ke dalam 4 indikator pernyataan, dan variabel terikat yaitu loyalitas mahasiswa yang dijabarkan ke dalam 4 indikator pernyataan. Dengan demikian maka ada total 48 indikator pernyataan kuesioner. Skala pengukuran menggunakan skala likert dengan 5 tingkat pengukuran yaitu (1) untuk sangat tidak setuju, (2) untuk tidak setuju, (3) cukup setuju, (4) setuju, dan (5) sangat setuju. Teknik analisis data menggunakan path analysis karena salah satu tujuan penelitian ini adalah menguji peran kepuasan dalam memediasi penagruh HEdPERF terhadap loyalitas mahasiswa.

\section{Hasil Penelitian dan Pembahasan}

\section{Profil Responden}

Dari hasil penyebaran kuisioner diperoleh informasi bahwa 60 responden $(75,6 \%)$ berjenis kelamin wanita, sedangkan 29 (24,4\%) responden adalah pria, berdasarkan program studi (prodi) responden maka dapat diketahui bahwa $65(54,6 \%)$ responden berasal dari prodi akuntansi dan 54 $(45,4)$ responden adalah mahasiswa prodi manajemen. Berdasarkan daerah asal responden, diperoleh informasi bahwa responden didominasi oleh mahasiswa yang berasal dari Kabupaten Gianyar sebanyak 48 (40,3\%) responden, kemudian dari Kabupaten Tabanan sebanyak 23 (19,3\%) responden, disusul berikutnya Kabupaten Badung sebanyak $16(13,45 \%)$ responden, Kota Denpasar sebanyak 15 (12,6\%) responden, Kabupaten Karangasem sebanyak 7 (5,9\%) responden, Kabupaten klungkung sebanyak 3 (2,5\%) responden, masing-masing Kabupaten Bangli, Kabupaten Buleleng, dan Kabupaten Jembrana sebanyak 2 (1,7\%) responden. Menurut status pekerjaan, mayoritas responden adalah mahasiswa yang belum bekerja sebanyak $91(76,5 \%)$ responden, sedangkan sisanya yang belum bekerja sebanyak $28(23,5 \%)$ responden.

\section{Deskripsi Jawaban Responden}

Analisis deskriptif bertujuan untuk memberikan deskripsi atau gambaran terkait dengan data dari suatu variabel penelitian. Rekapitulasi hasil rata-rata indikator, rata-rata dimensi, dan rata- 
rata variabel. Adapaun kriteria dan kategori penilaian jawaban kuisioner adalah sebagai berikut (Suharsono, $2010: 21$ ).

\section{Tabel 2. Kriteria Penilaian Jawaban Kuisioner}

\begin{tabular}{ccc}
\hline No & Kriteria & Kategori penilaian \\
\hline 1 & $1,00-1,80$ & Sangat Tidak Baik \\
2 & $1,81-2,60$ & Tidak Baik \\
3 & $2,61-3,40$ & Cukup Baik \\
4 & $3,41-4,20$ & Baik \\
5 & $4,21-5,00$ & Sangat Baik \\
\hline
\end{tabular}

Berdasarkan Tabel 3, untuk aspek akademik yaitu terdapat dua nilai rata-rata indikator yang berada berada dibawah rata-rata dimensi. Dengan indikator kelima "dosen mampu berkomunikasi dengan baik didalam kelas" sebesar 4,22 sebagai rata-rata tertinggi dan indikator ketujuh "tersedia waktu yang memadai dan fleksibel untuk berkonsultasi dengan dosen" sebesar 3,47 sebagai rata-rata terendah. Secara keseluruhan, dimensi aspek akademik menunjukkan nilai rata-rata 3,98 yang berarti lebih tinggi dari rata-rata variabel yaitu 3,81. Berdasarkan Tabel 3 dapat dikemukakan terdapat dua indikator yang termasuk dalam kateori Baik, sedangkan tujuh lainnya masuk kategori sangat baik.

Tabel 3. Deskripsi Jawaban Responden untuk Variabel HEdPERF Dimensi Aspek Akademik

\begin{tabular}{|c|c|c|c|c|c|}
\hline No. & It em & Total & $\begin{array}{l}\text { Rata-rata } \\
\text { Indikator }\end{array}$ & $\begin{array}{c}\text { Rata-rata } \\
\text { Dimensi }\end{array}$ & $\begin{array}{l}\text { Rata-rata } \\
\text { Variabel }\end{array}$ \\
\hline \multicolumn{6}{|c|}{ Aspek akademik } \\
\hline 1 & $\begin{array}{l}\text { Dosen memiliki pengetahuan untuk menjawab } \\
\text { pertanyaan terkait materi perkuliahan }\end{array}$ & 490 & 4.12 & \multirow{9}{*}{3.98} & \multirow{9}{*}{3.82} \\
\hline 2 & $\begin{array}{l}\text { Dosen membantu mahasiswa dengan cara yang sopan } \\
\text { dan baik }\end{array}$ & 493 & 4.14 & & \\
\hline 3 & $\begin{array}{l}\text { Dosen tidak pernah terlalu sibuk untuk membantu } \\
\text { mahasiswa }\end{array}$ & 416 & 3.50 & & \\
\hline 4 & $\begin{array}{l}\text { Dosen menunjukkan perilaku yang positif terhadap } \\
\text { mahasiswa }\end{array}$ & 497 & 4.18 & & \\
\hline 5 & $\begin{array}{l}\text { Dosen mampu berkomunikasi dengan baik di dalam } \\
\text { kelas }\end{array}$ & 503 & 4.23 & & \\
\hline 6 & $\begin{array}{l}\text { Dosen memberikan umpan balik/saran untuk kemajuan } \\
\text { mahasiswa }\end{array}$ & 495 & 4.16 & & \\
\hline 7 & $\begin{array}{l}\text { Tersedia waktu yang memadai dan fleksibel untuk } \\
\text { berkonsultasi dengan dosen }\end{array}$ & 414 & 3.48 & & \\
\hline 8 & $\begin{array}{l}\text { Dosen memiliki kompetensi dan pengalaman dalam } \\
\text { bidang ilmunya }\end{array}$ & 483 & 4.06 & & \\
\hline 9 & $\begin{array}{l}\text { Dosen memberi perhatian dan membantu mahasiswa } \\
\text { bila ada masalah }\end{array}$ & 475 & 3.99 & & \\
\hline
\end{tabular}

Sumber : data primer diolah, 2019.

Pada Tabel 4, dimensi aspek non akademik yang terdiri atas dua belas indikator, terdapat lima indikator yang nilainya rata-ratanya berada di bawah nilai rata-rata dimensi. Hasil rata-rata 
tertinggi sebesar 3.87 yaitu "data-data mahasiswa tersimpan baik dan akurat", sedangkan hasil ratarata terendah sebesar 3,06 yaitu "pertanyaan dan keluhan mahasiswa dapat diselesaikan dengan cepat”. Secara keseluruhan dimensi aspek non akademik berada di bawah rata-rata variabel yaitu sebesar 3,52. Berdasarkan Tabel 4 maka dapat dikemukakan bahwa terdapat emapt indikator yang termasuk dalam kategori cukup baik, sedangkan delapan indikator lainnya masuk kategori baik.

Tabel 4. Deskripsi Jawaban Responden untuk Variabel HEdPERF Dimensi Aspek Non Akademik

\begin{tabular}{|c|c|c|c|c|c|}
\hline No. & It em & Total & $\begin{array}{l}\text { Rata-rata } \\
\text { Indikator }\end{array}$ & $\begin{array}{c}\text { Rata-rata } \\
\text { Dimensi }\end{array}$ & $\begin{array}{c}\text { Rata-rata } \\
\text { Variabel }\end{array}$ \\
\hline \multicolumn{6}{|c|}{ Aspek non akademik } \\
\hline 10 & $\begin{array}{l}\text { Staff administrasi senantiasa siap membantu masalah } \\
\text { yang dihadapi mahasiswa }\end{array}$ & 422 & 3.55 & \multirow{12}{*}{3.52} & \multirow{12}{*}{3.82} \\
\hline 11 & Staf administrasi memberikan perhatian individual & 371 & 3.12 & & \\
\hline 12 & $\begin{array}{l}\text { Staf administrasi tidak pernah terlalu sibuk untuk } \\
\text { membantu mahasiswa }\end{array}$ & 384 & 3.23 & & \\
\hline 13 & Data-data mahasiswa tersimpan dengan baik dan akurat & 461 & 3.87 & & \\
\hline 14 & $\begin{array}{l}\text { Pelayanan yang dilakukan staf akademik dilaksanakan } \\
\text { sesuai dengan yang dijanjikan }\end{array}$ & 412 & 3.46 & & \\
\hline 15 & $\begin{array}{l}\text { Jam operasional layanan administrasi sesuai kebutuhan } \\
\text { mahasiswa }\end{array}$ & 398 & 3.34 & & \\
\hline 16 & $\begin{array}{l}\text { Staf menunjukkan sikap positif terhadap pekerjaan dan } \\
\text { mahasiswa }\end{array}$ & 439 & 3.69 & & \\
\hline 17 & $\begin{array}{l}\text { Terdapat komunikasi yang baik antara staf administrasi } \\
\text { dengan mahasi swa }\end{array}$ & 436 & 3.66 & & \\
\hline 18 & $\begin{array}{l}\text { Staf administrasi memiliki pengetahuan tentang } \\
\text { prosedur administrasi }\end{array}$ & 457 & 3.84 & & \\
\hline 19 & $\begin{array}{l}\text { Mahasiswa merasa aman dalam berhubungan dengan } \\
\text { FEBP UNHI }\end{array}$ & 454 & 3.82 & & \\
\hline 20 & $\begin{array}{l}\text { FEBP UNHI mampu menyediakan pelayanan sesuai } \\
\text { dengan waktu yang dijanjikan }\end{array}$ & 428 & 3.60 & & \\
\hline 21 & $\begin{array}{l}\text { Pertanyaan dan keluhan mahasiswa dapat diselesaikan } \\
\text { dengan cepat }\end{array}$ & 365 & 3.07 & & \\
\hline
\end{tabular}

Sumber : data primer, diolah 2019.

Hasil statistik untuk dimensi reputasi yang disajikan pada Tabel 5 menunjukkan bahwa terdapat tiga indikator dengan nilai rata-rata berada di bawah nilai rata-rata dimensi dan nilai ratarata variabel. Nilai rata-rata tertinggi yaitu indikator pertama "UNHI memiliki citra yang baik" sebesar 4,23 dan nilai rata-rata terendah sebesar 3,58 untuk indikator "lulusan FEBP UNHI mudah mendapatkan pekerjaan”. Rata-rata dimensi reputasi menunjukkan nilai di bawah rata-rata variabel yaitu sebesar 3,80. Dari total tujuh indikator pada dimensi reputasi sebagaimana disajikan pada Tabel 5 dapat diketahui bahwa enam indikator termasuk kategori baik, dan satu indikator yaitu "UNHI memiliki citra yang baik" termasuk kategori sangat baik. 
Tabel 5. Deskripsi Jawaban Responden untuk Variabel HEdPERF Dimensi Aspek Reputasi

\begin{tabular}{|c|c|c|c|c|c|}
\hline No. & Item & Total & $\begin{array}{l}\text { Rata-rata } \\
\text { Indikator }\end{array}$ & $\begin{array}{c}\text { Rata-rata } \\
\text { Dimensi }\end{array}$ & $\begin{array}{r}\text { Rata-rata } \\
\text { Variabel } \\
\end{array}$ \\
\hline \multicolumn{6}{|c|}{ Reputasi } \\
\hline 22 & UNHI memiliki citra yang baik & 504 & 4.24 & & \\
\hline 23 & Fasilitas belajar memadai dan sesuai dengan kebutuhan & 430 & 3.61 & & \\
\hline 24 & $\begin{array}{l}\text { FEBP UNHI melaksanakan program kuliah dengan } \\
\text { kualitas sangat baik }\end{array}$ & 459 & 3.86 & & \\
\hline 25 & $\begin{array}{l}\text { Tersedia fasilitas penunjang yang layak dan memadai } \\
\text { (bangku taman, kantin, dil) }\end{array}$ & 438 & 3.68 & 3.80 & 3.82 \\
\hline 26 & $\begin{array}{l}\text { Kampus berada di lokasi yang ideal, serta tata letak dan } \\
\text { tampilan fisik yang bagus }\end{array}$ & 455 & 3.82 & & \\
\hline 27 & FEBP UNHI memiliki kurikulum yang sesuai kebutuhan & 456 & 3.83 & & \\
\hline 29 & Lulusan FEBP UNHI mudah mendapatkan pekerjaan & 427 & 3.59 & & \\
\hline
\end{tabular}

Sumber : data primer, diolah 2019.

Dimensi akses yang ditampilkan pada Tabel 6 menunjukkan hasil yang baik, karena hanya satu indikator yang nilainya berada dibawah nilai rata-rata dimensi. Hasil rata-rata tertinggi yaitu 3,97 "mahasiswa bebas mengemukakan pendapat" sedangkan hasil rata-rata terendah yaitu 3,05 dengan pernyataan "staf administrasi mudah dihubungi via telepon”. Nilai rata-rata dimensi akses menunjukkan nilai di bawah rata-rata variabel yaitu sebesar 3,65. Dari tital tujuh indikator, hanya satu indikator yangtermasuk aktegori cukup baik, sedangkan enam lainnya masuk kategori baik.

Tabel 6. Deskripsi Jawaban Responden untuk Variabel HEdPERF Dimensi Akses

\begin{tabular}{|c|c|c|c|c|c|}
\hline No. & Item & Total & $\begin{array}{l}\text { Rata-rata } \\
\text { Indikator }\end{array}$ & $\begin{array}{c}\text { Rata-rata } \\
\text { Dimensi }\end{array}$ & $\begin{array}{c}\text { Rata-rata } \\
\text { Variabel }\end{array}$ \\
\hline \multicolumn{6}{|c|}{ Akses } \\
\hline 29 & Mahasiswa diperlakukan adil dan baik & 442 & 3.71 & \multirow{7}{*}{3.65} & \multirow{7}{*}{3.82} \\
\hline 30 & Mahasiswa bebas mengemukakan pendapat & 473 & 3.97 & & \\
\hline 31 & $\begin{array}{l}\text { Staf administrasi mampu menjaga kerahasiaan informasi } \\
\text { mahasiswa }\end{array}$ & 447 & 3.76 & & \\
\hline 32 & $\begin{array}{l}\text { Pihak Kampus membina dan mendukung organisasi } \\
\text { kemahasiswaan }\end{array}$ & 463 & 3.89 & & \\
\hline 33 & Staf administrasi mudah dihubungi via telepon & 364 & 3.06 & & \\
\hline 34 & $\begin{array}{l}\text { Kampus memiliki prosedur yang sederhana dan jelas } \\
\text { dalam melayani mahasiswa }\end{array}$ & 434 & 3.65 & & \\
\hline 35 & $\begin{array}{l}\text { Saran mahasiswa untuk perbaikan layanan FEBP UNHI } \\
\text { sangat dihargai }\end{array}$ & 421 & 3.54 & & \\
\hline
\end{tabular}

Sumber : data primer, diolah 2019.

Hasil statistik dimensi isu program pada Tabel 7 menggambarkan bahwa terdapat dua indikator yang berada diatas nilai rata-rata dimensi dari lima indikator yang ada. Nilai rata-rata tertinggi dengan pernyataan "program studi FEBP UNHI telah terakreditasi dengan baik" sebesar 4,00 dan nilai rata-rata terendah yaitu " terdapat program konseling bagi mahasiswa" sebesar 3,46. Nilai rata-rata dimensi isu program berada di bawah nilai rata-rata variabel sebesar 3,79. Secara keseluruhan, untuk variabel HEdPERF yang terdiri atas lima dimensi hanya terdapat satu dimensi 
yaitu aspek akademik yang memiliki nilai rata-rata dimensi di atas nilai rata-rata variabel, sedangkan empat dimensi lainnya berada di bawah rata-rata variabel. Seluruh indikator dari dimensi isu program termasuk kategori Baik.

Tabel 7. Deskripsi Jawaban Responden untuk Variabel HEdPERF Dimensi Aspek Isu Program

\begin{tabular}{|c|c|c|c|c|c|}
\hline No. & Item & Total & $\begin{array}{l}\text { Rata-rata } \\
\text { Indikator }\end{array}$ & $\begin{array}{c}\text { Rata-rata } \\
\text { Dimensi }\end{array}$ & $\begin{array}{c}\text { Rata-rata } \\
\text { Variabel }\end{array}$ \\
\hline \multicolumn{6}{|c|}{ Isu Program } \\
\hline 36 & $\begin{array}{l}\text { FEBP UNHI memiliki program studi dengan konsentrasi } \\
\text { (seperti manajemen pemasaran, manajemen SDM, dil) }\end{array}$ & 472 & 3.97 & & \\
\hline 37 & FEBP UNHI menyediakan kurikulum yang fleksibel & 450 & 3.78 & & \\
\hline 38 & Terdapat program konseling bagi mahasiswa & 412 & 3.46 & 3.79 & 3.82 \\
\hline 39 & FEBP UNHI memiliki program studi yang bervariasi & 446 & 3.75 & & \\
\hline & $\begin{array}{l}\text { Program studi FEBP UNHI telah terakreditasi dengan } \\
\text { baik }\end{array}$ & 476 & 4.00 & & \\
\hline
\end{tabular}

Sumber : data primer, diolah 2019.

Variabel kepuasan mahasiswa yang ditampilkan di Tabel 8 menunjukkan terdapat dua hasil rata-rata indikator berada di bawah hasil rata-rata dimensi. Hasil rata-rata tertiggi sebesar 4.04 dengan pernyataan "saya merasa senang menjadi mahasiswa FEBP UNHI" dan rata-rata terendah yaitu 3,57 "kualitas FEBP UNHI sesuai harapan saya". Rata-rata variabel kepuasan mahasiswa lebih tinggi dari rata-rata variabel HEdPERF yaitu 3,85. Berdasarkan Tabel 8 juga dapat dikemukakan bahwa seluruh indikator termasuk kategori Baik.

Tabel 8. Deskripsi Jawaban Responden untuk Variabel Kepuasan Mahasiswa

\begin{tabular}{llcc}
\hline No. Item & Total & $\begin{array}{c}\text { Rata-rata } \\
\text { Indikator }\end{array}$ & $\begin{array}{c}\text { Rata-rata } \\
\text { Variabel }\end{array}$ \\
\hline $\begin{array}{l}\text { Kepuasan Mahasiswa } \\
\quad \begin{array}{l}\text { Secara keseluruhan, saya puas terhadap kualitas FEBP } \\
\text { UNHI }\end{array}\end{array}$ & 456 & 3.83 & \\
$\quad \begin{array}{l}\text { Menjadi mahasiswa FEBP UNHI adalah pilihan yang } \\
\text { tepat }\end{array}$ & 471 & 3.96 & 3.85 \\
43 & 426 & 3.58 & \\
44 & Kualitas FEBP UNHI sesuai dengan harapan saya & & \\
\hline
\end{tabular}

Sumber : data primer, diolah 2019

Hasil variabel terakhir yaitu loyalitas mahasiswa sebagaimana disajikan pada Tabel 9 adalah terdapat satu indikator yang nilainya dibawah nilai rata-rata dimensi. Nilai rata-rata tertinggi yaitu 4,36 dengan pernyataan "saya akan menceritakan hal-hal positif mengenai FEBP UNHI" dan rata-rata terendah 3,62 yaitu “jika FEBP UNHI membuka program s2 (manajemen/akuntansi) maka saya akan melanjutkan kuliah di FEBP UNHI”. Rata-rata variabel loyalitas mahasiswa 
menunjukkan nilai yang lebih tinggi baik dari variabel HEdPERF maupun variabel kepuasan mahasiswa. Dari empat indikator pengukuran variabel loyalitas mahasiswa, terdapat dua indikator yang termasuk kategori Baik, sedangkan dua lainnya termasuk kategori Sangat Baik.

Tabel 9. Deskripsi Jawaban Responden untuk Variabel Loyalitas Mahasiswa

\begin{tabular}{lccc}
\hline \multicolumn{1}{c}{ Item } & Total & $\begin{array}{c}\text { Rata-rata } \\
\text { Indikator }\end{array}$ & $\begin{array}{c}\text { Rata-rata } \\
\text { Variabel }\end{array}$ \\
\hline $\begin{array}{l}\text { Loyalitas Mahasisw a } \\
\quad \begin{array}{l}\text { Saya akan menceritakan hal-hal positif mengenai FEBP } \\
\text { UNHI }\end{array}\end{array}$ & 520 & 4.37 & \\
$\begin{array}{l}\text { Saya akan merekom endasikan FEBP UNHI kepada } \\
\text { orang lain }\end{array}$ & 500 & 4.20 & 4.11 \\
$\quad \begin{array}{l}\text { Jika FEBP UNHI membuka program S2 } \\
\text { (Manajem en/Akuntansi) maka saya akan melanjutkan } \\
\text { kuliah di FEBP UNHI }\end{array}$ & 431 & 3.62 & \\
$48 \quad$ Saya merasa bangga sebagai mahasiswa FEBP UNHI & 506 & 4.25 & \\
\hline
\end{tabular}

Sumber : data primer, diolah 2019

\section{Uji Reliabilitas dan Validitas Instrumen}

Uji validitas dan reliabilitas dilakukan pada keseluruhan variabel dalam penelitian ini. Berdasarkan hasil uji validitas dan reliabilitas instrumen, maka dapat dikemukakan bahwa instrumen penelitian yang digunakan telah memenuhi persyaratan validitas dan reliabilitas, dimana seluruh indikator memiliki nilai koefisien korelasi di atas 0,30 sebagai syarat minimal uji validitas dan nilai koefisien korelasi di atas 0,60 sebagai syarat minimal uji reliabilitas instrumen. Setelah melakukan uji validitas dan reliabilitas instrumen, maka langkah selanjutnya adalah melakukan interprestasi terhadap hasil uji pengaruh langsung, tidak langsung, dan pengaruh total yang dapat dilihat pada Tabel 11 berikut.

Tabel 11. Pengaruh Langsung, Pengaruh Tidak Langsung, dan Pengaruh Total

\begin{tabular}{lccc}
\hline Variabel & $\begin{array}{c}\text { Pengaruh } \\
\text { Langsung }\end{array}$ & $\begin{array}{c}\text { Pengaruh tidak } \\
\text { langsung melalui } \\
\text { kepuasan }\end{array}$ & $\begin{array}{c}\text { Pengaruh } \\
\text { Total }\end{array}$ \\
\hline HEdPERF $\longrightarrow$ Loyalitas & 0.042 & 0.221 & 0.263 \\
HEdPERF $\longrightarrow$ Kepuasan & 0.677 & - & 0.677 \\
Kepuasan $\longrightarrow$ Loyaltas & 0.325 & - & 0.325 \\
\hline
\end{tabular}

Sumber : data primer, diolah 2019

Hasil penelitian menunjukkan variabel HEdPERF berpengaruh positif namun tidak signifikan terhadap loyalitas mahasiswa yang dibuktikan dengan nilai koefisien jalur sebesar 0,042 dan nilai sig 0,72.>0,05 sehingga $\mathrm{H} 1$ yang berbunyi HEdPERF berpengaruh positif dan signfikan terhadap loyalitas mahasiswa tidak terbukti kebenarannya. Hasil ini memberikan makna bahwa 
apabila terdapat peningkatan kinerja HEdPERF maka dampaknya terhadap loyalitas adalah sangat kecil atau dengan kata lain loyalitas yang tercipta sangat rendah. Hasil penelitian juga menunjukkan dukungan terhadap hipotesis kedua (H2) yang berbunyi HEdPERF berpengaruh positif dan signifikan terhadap kepuasan mahasiswa yang dibuktikan dengan nilai koefisien jalur sebesar 0.677 dan nilai sig. $0,00<0,05$. Makna dari hasil penelitian ini adalah semakin tinggi atau meningkatnya kinerja HEdPERF maka akan diikuti dengan peningkatan kepuasan mahasiswa.

Hasil berikutnya juga menunjukkan adanya dukungan terhadap hipotesis $3(\mathrm{H} 3)$ yang berbunyi kepuasan berpengaruh positif dan signifikan terhadap loyalitas yang dibuktikan dengan nilai koefisien jalur sebesar 0.325 dan nilai sig. $0,00<0,05$; dan hasil ini memberikan suatu gambaran bahwa apabila terjadi kepuasan mahasiswa maka loyalitas mahasiswa juga akan ikut mengalami peningkatan. Untuk menjawab hipotesis $4(\mathrm{H} 4)$ yang mengatakan kepuasan memediasi pengaruh HEdPER terhadap loyalitas mahasiswa maka dilakukan uji SOBEL dan berdasarkan hasil uji tersebut diperoleh nilai $\mathrm{Z}$ hitung $(2,647)>\mathrm{Z}$ tabel $(1,96)$ sehingga $\mathrm{H} 4$ dapat diterima. Hasil ini memberikan suatu makna bahwa semakin membaik atau meningkatnya HEdPERF maka akan menciptakan kepuasan mahasiswa yang pada akhirnya akan mendorong mahasiswa tersebut menjadi loyal yang ditunjukkan dengan menceritakan hal-hal positif, memberikan rekomendasi kepada orang lain, akan melanjutkan studi ke jenjang S2, dan menunjukkan kebanggannya sebagai mahasiswa FEBP UNHI.

\section{Simpulan}

Berdasarkan hasil analisis data maka dapat disimpulkan sebagai berikut:

1. HEdPERF berpengaruh positif namun tidak signifikan terhadap loyalitas mahasiswa dengan koefisien jalur 0.042 dan nilai sig. $0,72>0.05$.

2. HEdPERF berpengaruh positif dan signifikan terhadap kepuasan mahasiswa dengan koefisien jalur sebesar 0,677 dan nilai sig. 0,00<0,05.

3. Kepuasan berpengaruh positif dan signifikan terhadap loyalitas mahasiswa dengan koefisien jalur sebesar 0,325 dan nilai sig. $0,00<0,05$.

4. Kepuasan memediasi pengaruh HEdPERF terhadap loyalitas mahasiswa dengan nilai $Z$ hitung $(2,647)>Z$ tabel $(1,96)$.

\section{Implikasi}

Dari segi teoritis, penelitian ini memberikan suatu bukti bahwa kualitas layanan pendidikan tinggi khususnya HEdPERF tidak mampu secara langsung (direct) mendorong terciptanya loyalitas mahasiswa, dan kepuasan memegang peranan penting dalam memediasi pengaruh HEdPERF terhadap loyalitas mahasiswa. 
Dari segi praktis atau manajerial, penelitian ini memberikan beberapa kontribusi penting. Pertama, pentingnya untuk memciptakan kepuasan terlebih dahulu sebelum menciptakan loyalitas. Ini dibuktikan dari peran kepuasan sebagai mediasi antara HEdPERF dan loyalitas. Kedua, statistik deskriptif masing-masing dimensi HEdPERF menunjukkan nilai rata-rata dimensi yang lebih rendah dibandingkan dengan nilai rata-rata variabel, kecuali untuk dimensi aspek akademik yang menunjukkan nilai rata-rata lebih tinggi dari rata-rata variabel. Hasil ini dapat menjadi acuan bagi pengelola FEBP UNHI untuk meningkatkan kinerja dari dimensi-dimensi HEdPERF yang disertakan dalam penelitian ini. Ketiga, hasil statistik deskriptif juga dapat digunakan sebagai acuan untuk meningkatkan kinerja indikator-indikator dari masing-masing dimensi, khususnya yang memiliki nilai rendah atau berada di bawah rata-rata dimensi. FEBP UNHI dapat melakukan evaluasi secara berkala terhadap kinerja HEdPERF.

\section{Penelitian selanjutnya}

Bagi penelitian berikutnya, diharapkan dapat mengembangkan penelitian ini dengan memperluas sampel penelitian yang tidak hanya mahasiswa Fakultas Ekonomi tapi juga melibatkan mahasiswa dari fakultas lain. Selain itu juga dapat dikembangkan dengan menambahkan variabel lain sebagai variabel mediasi seperti kepercayaan atau menempatkan variabel moderasi untuk meningkatkan pengaruh HEdPERF terhadap loyalitas seperti akreditasi institusi. Untuk mendapatkan hasil yang lebih rinci mengenai pengaruh HEdPERF terhadap kepuasan dan loyalitas maka penelitian berikutnya dapat menguji pengaruh masing-masing dimensi HEdPERF serta peran kepuasan memediasi pengaruh dimensi HEdPERF terhadap loyalitas.

\section{Daftar Pustaka}

Abdullah, F. 2005. The Development of HEdPERF : A New Measuring Instrument of Service Quality for the Higher Education Sector. International Journal of Consumer Studies, 30, 6, pp. $569-581$

Abdullah, F. 2006. Measuring service quality in higher education: HEdPERF versus SERVPERF. Marketing Intelligence and Planning, Vol. 24 No. 1, pp. 31-47.

Ali, F. dan Amin, M. 2014. The Influence of Physical Environment on Emotions, Customer Satisfaction and Behavioural Intentions in Chinese Resort Hotel Industry. Journal for Global Business Advancement, Vol. 7 No. 3, pp. 249-266.

Ali, F., Khan, A. dan Rehman, F. 2012. An assessment of the service quality using gap analysis: a study conducted at Chitral, Pakistan. Interdisciplinary Journal of Contemporary Research in Business, Vol. 4 No. 3, pp. 259-266.

Ali, F., K. Hussain., P.K. Nair., dan N. A. Ragavan. 2018. Does Higher Education ervice Quality Effect Student Satisfaction, Imagen, and Loyalty? : A Study of International Students in Malaysian Public Universities. Quality Assurance in Education, Vol. 24, No. 1, pp. 70-94

Alves, H., dan M. Raposo. 2010. The Influence of University Image on Student Behavior. International Journal of Educational Management, 24(1), 73-85.

Angell, R.J., Heffernan, T.W. dan Megicks, P. 2008. Service quality in postgraduate education. Quality Assurance in Education, Vol. 16 No. 3, pp. 236-54. 
Annamdevula, S., dan R.S. Bellamkonda. 2016a. The Effect of Service Quality on Student Loyalty : the Mediating Role of Student Satisfaction. Journal of Modelling in Management, Vol. 11, No, 2, pp. 446-462

Annamdevula, S., dan R. S. Bellakomda. 2016b. Effect of Student Perceived Service Quality on Student Satisfaction, Loyalty and Motivation in Indian Universities : Development of HiEduQual. Journal of Modelling in Management, Vol. 11, Iss. 2

Anonim. 2019. Top Universities in Bali, 2019 Bali University Ranking. Available at : https://www.4icu.org/id/bali/. Access at October 31 ${ }^{\text {st }}, 2019$

Becket, N., dan M. Bookes. 2006. Evaluating Quality Management in University Departments. Quality Assurance in Education, Vol. 14, No. 2, pp. 123-142

Bloemer, J. dan K. de Ruyter. 2010. Customer loyalty in high and low involvement service settings: The moderating impact of positive emotions. Journal of Marketing Management, 314-330

Carter, P. 2014. A case study of student satisfaction. Proceedings of CLaSIC, Kyushu Sangyo University.

Caruana, A. 2002. Service loyalty: the effects of service quality and the mediating role of customer satisfaction. European Journal of Marketing, Vol. 36 No. 7, pp. 811-828.

Chang-Li, S. 2012. Exploring the Relationship Among Service Quality, Customer Loyalty and Word Of Mouth for Private Higher Education in Taiwan. Asia Pacific Management Review, 18(4), pp. 375-389

Clemes, M. D., Cohen, D. A. dan Y. Wang. 2013. Understanding Chinese University Students' Experiences: an Empirical Analysis. Asia Pacific Journal of Marketing and Logistics, Vol. 25 No. 3, pp. 391-427.

Diab, D., H. Mohamed., O. Shidwan., dan I.H.F. Mansour. 2016. Investigation of Dineserv Dimensions on Customer Satisfaction \& Loyalty : Evidences From the Restaurat Industry in Sudan. NCM Conferences

Dlacic, J., M.Arslanagic., S. Kadic-Maglajlic., S. Markovic. Dan S. Raspor. 2013. Exploring Perceived Service Quality, Perceived Value, and Repurchase Intention In Higher Education Usingstructural Equation Modelling. Total Quality Management \& Business Excellence, 25(1-2), 141-157.

Duque, L.C 2013. A Framework Analyzing Higher Education Performance: Student's Satisfaction, Perceived Learning Outcomes and Dropout Intentions. Total Quality Management \& Business Excellence Journal, 25:1-2, 1-21.

Elliott, K.M. dan D. Shin. 2002. Student Satisfaction: An Alternative Approach to Assessing This Important Concept. Journal of Higher Education Policy and Management, Vol. 24 No. 2, pp. 197-209

Faizan, A., Y. Zhou., K. Hussain., P.K. Nair., dan N.A. Ragavan. 2016. Does Higher Education Service Quality Effect Student Satisfaction, Image and Loyalty? A Study of International Students in Malaysian Public Universities. Quality Assurance in Education, 24(1), pp. 70 94.

Ganic, E., V. B. Hodovic., dan M. A. Kalajdzic. 2018. Effects of Servperf Dimension on Students Loyalty-Do You Know What is Behind the Scene. International Journal of Business and Social Science, Vol. 9, No. 2.

Hassan, S., dan M.F.Shamsudin. 2019. Measuring the Effect of Service Quality and Corporate Image on Student Satisfaction and Loyalty in Higher Learning Institutes of Technical and Vocational and Training. International Journal of Engineering and Advanced Technology, Volume 8, Issue 5c

Helgesen, O. dan E. Nesset. 2007. What Accounts For Students' Loyalty? Some Field Study Evidence. International Journal of Educational Management, Vol. 21 No. 2, pp. 126- 143.

Helgesen, O. dan E. Nesset. 2011. Does LibQUAL+ Account For Student Loyalty To A University College Library?. Quality Assurance in Education, Vol. 19 No. 4, pp. 413-440. 
Ho, L.A., Y.K. Kuo. dan T.H. Kuo. 2013. How A Training Institute Acquires Learner Satisfaction And Loyalty Under Economic Recession. Total Quality Management \& Business Excellence, 25(1-2), 158-174.

Huili, Y. dan Y. Jing. 2012. Empirical Research and Model Building About Customer Satisfaction Index on Postgraduate Education Service Quality. Canadian Social Science, Vol. 8 No. 1, pp. 108-111.

Ibrahim, M.Z., M.N.A. Rahman., dan R.M.Yasin. 2014. Determining Factor of Students Satisfaction with Malaysian Skills Training Institutes. International Education Studies, Vol. 7, No. 6.

Icli, G. dan N. Anil, N. 2014. The HEDQUAL Scale: A New Measurement Scale of Service Quality for MBA Programs in Higher Education. South African Journal of Business Management, 45, 31-43.

Jancey, J. dan Burns, S. 2013. Institutional Factors and the Postgraduate Student Experience. Quality Assurance in Education, Vol. 21 No. 3, pp. 311-322.

Jiewanto, A., Laurens, C. dan L. Nelloh. 2012. Influence of Service Quality, University Image, and Student Satisfaction toward WOM Intention: A Case Study on Universitas Pelita Harapan Surabaya. Procedia - Social and Behavioral Sciences, Vol. 40, pp. 16 - 23

Kheiry, B. 2012. University Intellectual Image Impact on Satisfaction and Loyalty of Students (Tehran Selected Universities). African Journal of Business Management, 6(37), 1020510211.

Kuh, G.D. dan S. Hu. 2001. The effects of student-faculty interaction in the 1990s. Review of Higher Education, Vol. 24 No. 3, pp. 309-321.

Lazibat, T., T. Bakovic., dan I, Duzevic. 2015. How Perceived Service Quality influences Students Satisfaction?Teachers and Students Perspective. Total Quality Management \& Business Excellence. Vol. 25, No. 8, pp. 923-934

Law, D.C.S. 2013. Initial Assessment of Two Questionnaires for Measuring Service Quality in the Hong Kong Post-Secondary Education Context. Quality Assurance in Education, Vol. 21, No. 3., pp. 231-246.

Li, S.J., Y.Y. Huang., dan M.M. Yang. 2011. How Satisfaction Modifies the Strength of The Influence Of Perceived Service Quality on Behavioural Intentions. Leadership in Health Services, 24(2), 91-105.

Marzo-Navarro, M., M. Pedraja-Iglesias. dan M.P. Rivera-Torres. 2005. Measuring Customer Satisfaction in Summer Courses. Quality Assurance in Education, Vol. 13 No. 1, pp. 53-65.

F.F. Reichheld., dan C. Detrick. 2003. Loyalty : A Prescription For Cutting Costs. Marketing Management, 12 (5): 24-5.

Ryu, K., H. Lee., dan W. Kim. 2012. The Influence of The Quality of The Physical Environment, Food, and Service on Restaurant Image, Customer Perceived Value, Customer Satisfaction, and Behavioral Intentions. International Journal of Contemporary Hospitality Management,Vol. 24 No. 2, pp. 200-223.

Said, L. R. 2017. Pengaruh Kualitas Layanan Terhadap Motivasi dan Loyalitas Mahasiswa Dengan Kepuasan Sebagai Variabel Mediasi (Studi Pada Poltekkes Kemenkes Banjarmasin). Jurnal Wawasan Manajemen, Vol. 5, No. 2.

Salim, A., M. L. Singgih., dan E. Nurmantio. 2011. Pengukuran Kualitas Layanan Menggunakan SERVQUAL dan Confirmatory Factor Analysis (CFA) (Studi Kasus pada Jurusan Teknik Industri Universitas XYZ). Prosiding Seminar Nasional Manajemen Teknologi XIII.

Schertzer, C.B. dan S.M.B. Schertzer. 2004. Student Satisfaction and Retention: A Conceptual Model. Journal of Marketing for Higher Education, Vol. 14 No. 1, pp. 79-91. 
Silva, D.S., G.H.S.M. de Moraes, I.K.Makiya., dan F.I.G. Caesar. 2017. Measurement of Perceived Service Quality in Higher Education Institutions : A Review of HEdPERF Scale Use. Quality Assurance in Education

Seth, N., Deshmukh, S.G. and Vrat, P. 2005. Service Quality Models: A Review. International Journal of Quality and Reliability Management, Vol. 22 No. 9, pp. 913-949.

Stukalina, Y. 2014.Identifying Predictors Of Student Satisfaction And Student Motivation In The Framework of Assuring Quality in the Delivery of Higher Education Services. Business, management and Education, 12(1), 127-137

Sultan, P. dan H.Y. Wong. 2012. Service Quality in a Higher Education Context : An Integrated Model. Asia pacific journal of marketing and logistics, 24(5), pp. 755-784.

Sultan, P. dan H.Y. Wong. 2013. Antecedents and Consequences of Service Quality in a Higher Education Context: A Qualitative Research Approach. Quality Assurance in Education, Vol. 21 No. 1, pp. 70-95.

Sureshchandar, G.S., C. Rajendran., dan R.N. Anantharaman. 2003. Customer Perceptions Of Service Quality in The Banking Sector Of a Developing Economy: a Critical Analysis", International Journal of Bank Marketing, Vol. 21 No. 5, pp. 233-242.

Usman U., dan S.S.M. Mokhtar. 2016. Analysis of Service Quality, University Image and Student Satisfaction on Student Loyalty in Higher Education in Nigeria. International Business Management.

Wu, H., R.D. Tennyson., dan T. Hsia. 2010. A Study of Student Satisfaction in a Blended ELearning System Environment. Computer and Education, 55, 155-164.

Zeithaml, V.A. 1988. Consumer Perceptions Of Price, Quality And Value: A Means-End Model and Synthesis of Evidence. Journal of Marketing, Vol. 52, pp. 2-2 